\title{
2-((2-Hidroksibenziliden)amino)-4-Nitrofenol Schiff Bazının Teorik Olarak İncelenmesi ve Bazı Quantum Kimyasal Parametrelerinin Hesaplanması
}

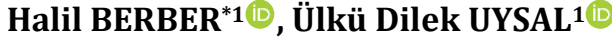 \\ ${ }^{1}$ Eskişehir Teknik Üniversitesi, Fen Fakültesi, Kimya Bölümü, 26470, Eskişehir, Türkiye
}

(Alınış / Received: 08.07.2021, Kabul / Accepted: 04.11.2021, Online Yayınlanma / Published Online: 25.12.2021)

\section{Anahtar Kelimeler}

Konformasyon analizi,

Schiff bazl,

Tautomerizm,

H-bağl,

NBO,

DFT
Özet: 2-((2-Hidroksibenziliden)amino)-4-nitrofenol Schiff bazı bileşiğinin konformasyon analizi; DFT yönteminde, B3LYP metodu ve 6-311G++(d,p) temel seti ile yapılmış ve bileşiğin cis ve trans izomerlerinin konformasyonları teorik olarak hesaplanarak en kararlı konformasyonlar belirlenmiştir. Toplam enerjileri ve dihedral açıları hesaplanarak keto ve enol formlarının tautomer kararlılıkları belirlenmiştir. Enol tautomer formundaki molekülün keto tautomer formuna dönmesi sürecindeki enerji değişimleri yorumlanmıştır. Bileşiğin kararlı konformasyonu ile IR, ${ }^{1} \mathrm{H}$ ve ${ }^{13} \mathrm{C}$ NMR, UV-Vis., dipol moment, H-bağları, atomik yükleri (NBO), HOMO, LUMO ve bant aralığı enerjileri $\left(\mathrm{E}_{G A P}\right)$, moleküler elektrostatik potansiyel şekli (MEP) ve çözücü erişilebilir yüzey alanı (SASA) hesaplamaları yapılmıștır. Molekülün optik ve metalik iletkenlik gibi elektronik özelliklere sahip aday molekül olduğu düşünülmektedir. SASA şeklinden molekülün polar ve polar protik çözücülerle güçlü etkileşim merkezlerinin olduğu ve biyolojik sistemler için de aktif merkezler içerdiği düşünülmektedir.

\section{The Conformation Analysis and Certain Theoretical Calculations of 2-((2- hydroxybenziliden)amino)-4-nitrophenol}

\section{Keywords}

Conformation analysis,

Schiff base,

Tautomerism,

H-bond,

NBO,

DFT

\begin{abstract}
A conformation analysis of Schiff base compound 2-((2hydroxybenziliden)amino)-4-nitrophenol was done by DFT (B3LYP method and 6$311 \mathrm{G}++(\mathrm{d}, \mathrm{p})$ basis set) method and possible cis and trans conformations were also calculated theoretically. Then the most stable conformation was determined. By calculating total energies and dihedral angles, the tautomer stabilities of keto and enol forms of the molecules were determined. The energy changes during conversion of the molecule in the form of an enol tautomer, to the keto form has been interpreted. The IR, ${ }^{1} \mathrm{H},{ }^{13} \mathrm{C}$ NMR and UV-Vis. spectra, dipole moment, $\mathrm{H}$-bond, natural bond orbital (NBO), HOMO, LUMO and bant gap energy (E $\mathrm{E}_{\mathrm{GAP}}$ ), solvent accessibility surface (SASA) and molecular electrostatic potentials values (MEP) were calculated for the most stable conformation of the molecule. From its SASA shape, the molecule is thought to have strong interaction centers with polar and polar protic solvents and to contain active centers for biological systems. The molecule is thought to be a candidate molecule with electronic properties such as optical and metallic conductivity.
\end{abstract}

\section{Giriş}

Schiff bazları gibi küçük organik moleküller kolay ve düşük maliyetle sentezlenebilmeleri nedeniyle uzunca yıllardır büyük ilgi çekmektedir. Çözücülerle etkileşim kapasitesi ve farklı yük taşımaları onların optoelektronik uygulamalarına olanak sağlar [1-3]. Bu moleküller; diodlar, fotovoltaikler, laserler, mikroelektronikler, transistörler ve dedektörler gibi fonksiyonel optoelektroniklerin dizaynında büyük rol alır [4]. Bu küçük moleküllerin moleküller arası etkileșimlerini arttırmak için çeșitli heteroatomların bağlanmasıyla elektron delokalizasyonu ve yüksek yük taşıma kapasitesi kolaylıkla arttırılabilir. Literatürde Schiff bazları ve komplekslerinin kemosensör [5], katalitik [6], solvatokromik [7], boyar madde [8] olarak kullanımlarına ve sıvı kristal özellikleri [9] nedeniyle de birçok alanda kullanımlarına yönelik çalışmalar mevcuttur. Ayrıca Schiff bazları biyolojik aktivite çalışmalarında da kullanılmaktadır [10-12]. Ancak aktivite mekanizması tam olarak aydınlatılamadığından Schiff bazı ile ilgili 
yapı-aktivite çalışmaları son yıllarda ağırlık kazanmıștır [13-17].

$\mathrm{Bu}$ makale kapsamında çalışılan 2-((2hidroksibenziliden)amino)-4-nitrofenol (8S5) Schiff bazı bir azometin bağı, bir sübstitüe $-\mathrm{NO}_{2}$ grubu ve iki sübstitüe -OH grubu içermektedir. Söz konusu ligant ilk kez Argauer ve arkadaşları tarafından metal şelatlarının floresans çalışmalarında kullanılmak üzere sentezlenmiştir [18]. Literatürde 8S5 ligandının Vanadyum (IV) ile olușturduğu Schiff bazlarının sentez, spektroskopi, elektrokimya ve termal uygulamalarına [19], $\mathrm{Fe}^{3+}, \mathrm{Mn}^{2+}$ ve $\mathrm{Ru}^{2+}$ iyonları ile ekstraksiyonuna dayalı spektrofotometrik tayinlerine [20-22] ve antimikrobiyal aktivitesinin araştırılmasına [23] yönelik çalışmalar mevcuttur. Ancak literatürde 8S5 kodlu Schiff bazına ait herhangi bir teorik çalışmaya rastlanamamıştır.

Grubumuz tarafından bu çalışmada kullanılan Schiff bazı ve ilgili bir seri Schiff bazı daha önceki çalışmalarımızda sentezlenmiş, deneysel ve teorik çalışmalardan oluşan çeşitli çıktılarla literatüre katkı sağlanmıştır [13-17, 24-27]. Bu çalışmada, 2-((2hidroksibenziliden)amino)-4-nitrofenol (8S5) Schiff bazının en kararl cis ve trans izomerlerinin konformasyonları (Tablo 1) teorik hesaplamalarla belirlenerek olası en kararlı konformasyonlar belirlenmiştir. Toplam enerjileri ve dihedral açıları hesaplanarak keto ve enol tautomer formlarının tautomer kararılıkları belirlenmiştir.

Molekülün enol formundaki (8S5_m1_1_E) H17 ve H18'in keto formuna (8S5_m1_1_K1 ve 8S5_m1_1_K2) dönüşümünde N8'e bağlanması sürecinde bağ uzunluğu ile enerji değişimine ait konformasyon incelenmiştir.

\section{Materyal ve Metot}

Teorik hesaplamalarda; CS ChemBioDraw Ultra 16.0.1.4, Microsoft Windows [28], Gaussian09 [29] ve GaussView 5.0.9 [30] programları kullanılmıștır. Tüm hesaplamalar DFT yönteminde, B3LYP metodu ve 6$311 \mathrm{G}++(\mathrm{d}, \mathrm{p})$ temel setleri kullanılarak yapılmıştır. Optimizasyon, scan konformasyon (Scanning Potential Energy Surfaces) ve NBO (Natural Bond Orbital) hesaplamaları vakumda yapılmıştır. NMR hesaplamaları $D M S O$ 'da yapılmıştır. Uyarma enerjileri (UV-Vis.); aseton $(A S)$, asetonitril $(A S C N)$, kloroform $\left(\mathrm{CHCl}_{3}\right)$, diklorometan $(\mathrm{DCM}), \mathrm{N}, \mathrm{N}$-dimetilformamit $(D M F)$, dimetil sülfoksit (DMSO), etil alkol $(E T O H)$, metil alkol $(M E T O H)$ ve vakum $(V)$ fazlarında yapılmıştır.

\section{Bulgular}

\subsection{Cis-Trans izomerliği analizi}

Konformasyon analizi için; ChemDraw programında çizilen cis ve trans izomer bileşiklerinin geometrilerine ait enerjileri Chem3D programında MM2 ile minimize edilerek belirlenmiştir. Ayrıca moleküllerin cis ve trans izomerlerinin konformasyonlarl; $\quad$ MarvinSketch $\quad 19.27 .0$ programinda [31] konformasyon hesaplaması ile belirlenmiștir. Bu konformasyonlar tekrar Chem3D programında MM2 ile minimize edilerek enerjileri belirlenmiștir. Bu çalışmalar sonunda en kararlı trans izomeri (8S5_m1_1) ve en kararlı cis izomeri (8S5_m50_50) konformasyonları belirlenmiştir (Ek AD) ve Tablo 1'de verilmiștir.

8S5_m1_1 kararlı trans izomere ait konformasyonu kullanılarak olası tautomer formları çizilmiştir. Çizilen enol tautomer formu 8S5_m1_1_E, keto tautomer formlarl ise 8S5_m1_K1 ve 8S5_m1_K2 olarak isimlendirilmiştir (Şekil 1). Keto tautomer formları da Chem3D programında MM2 ile minimize edilmiş ve enerjisi hesaplanmıștır (Ek D).

Tablo 1. Schiff bazının en kararlı cis ve trans izomerleri
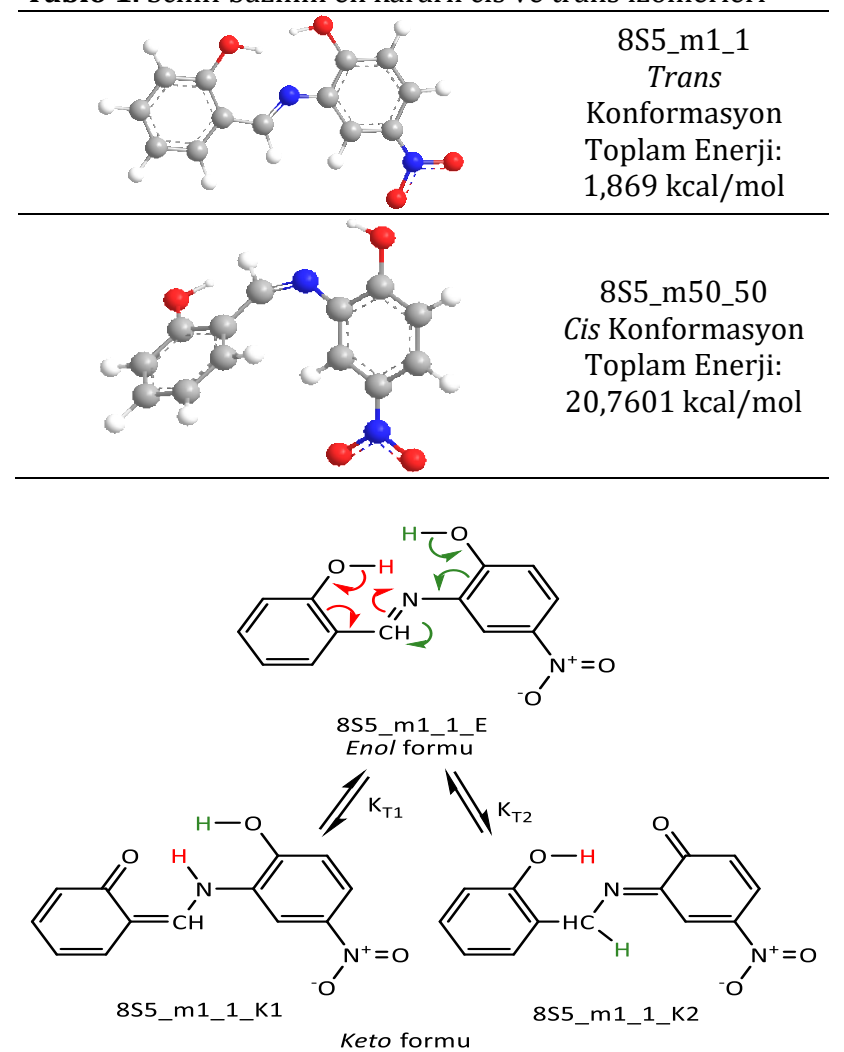

Şekil 1. Çalışılan bileșiğin enol ve keto tautomer formları. (E: Enol formu, K1: Olası tautomer formu, K2: Olası tautomer formu)

Belirlenen enol (8S5_m1_1_E) ve keto (8S5_m1_1_K1 ve 8S5_m1_1_K2) tautomer formu bileşiklerinin optimizasyon hesaplamaları yapılmıștır. Ayrıca bu bileşiklerin scan konformasyon hesaplamaları yapılarak kararlı konformasyonları tekrar araştırılmıştır. Yapılan tüm konformasyon hesaplamaları sonunda 3_8S5_m1_1_E_opt (Ek E), 2_8S5_m1_1_K1_opt (Ek F) ve 1_8S5_m1_1_K2_opt (Ek G) en kararlı konformasyonlar olarak belirlenmiştir (Tablo 2). Hesaplamalarda bu konformasyonlar kullanılmıștır. 
Tablo 2. Schiff bazı bileșiğin enol ve keto formlarının konformasyon hesaplamaları

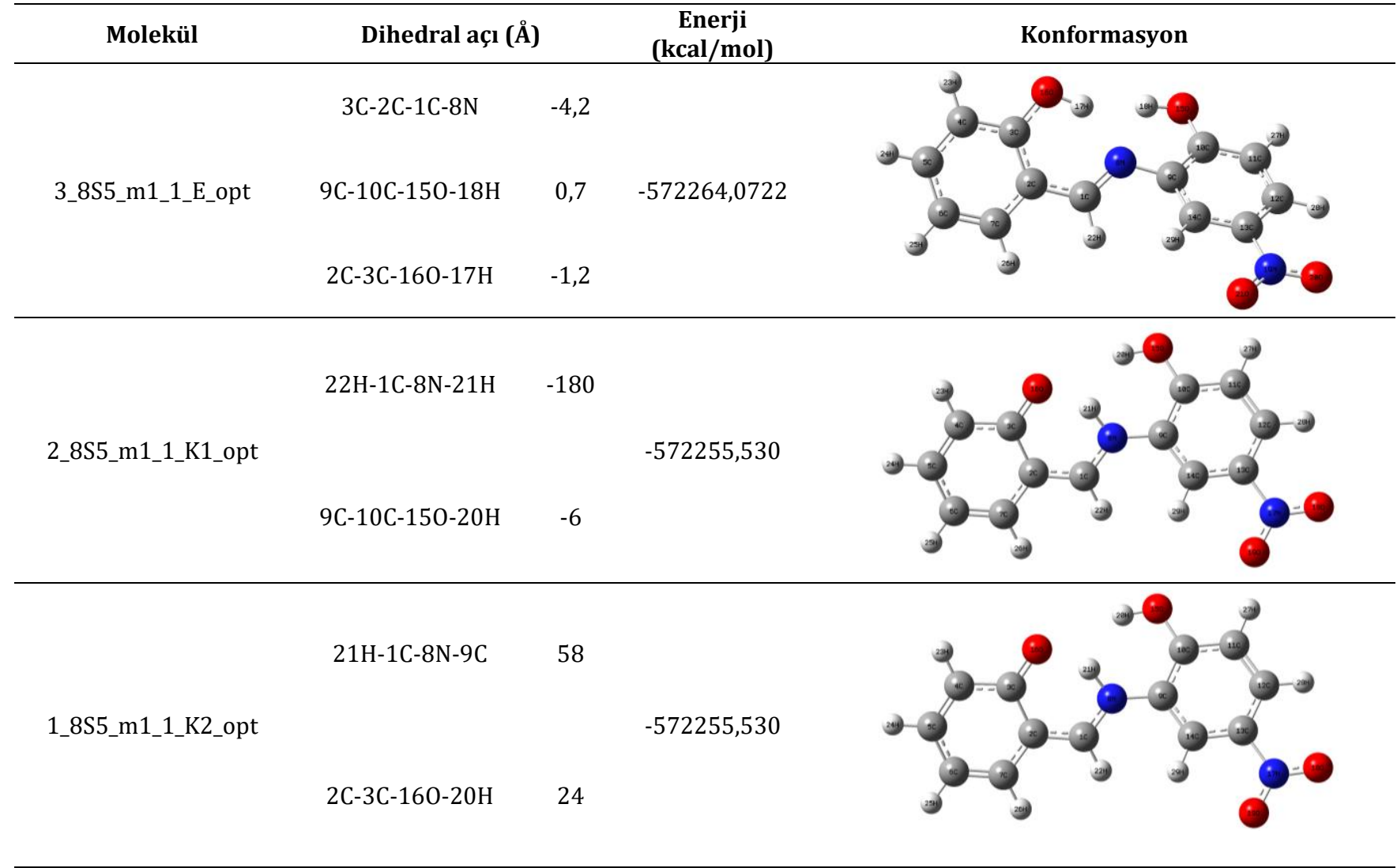

\subsection{Keto-enol tautomerlik analizi}

Moleküllerin olası tautomer formlarının bilinmesi, reaksiyonların ve spektroskopik analizlerin sonuçlarının anlaşılabilmesi açısından önemlidir. Molekülünün (3_8S5_m1_1_E_freq) ve olası tautomer formlarinin (3_8S5_m1_1_K1 ve 3_8S5_m1_1_K2) vakum ve çözücü fazında yapılan hesaplama sonuçları Tablo 3'de verilmiştir.

$\mathrm{K}_{\mathrm{T} 1}$ tautomeri, enol formu (3_8S5_m1_1_E_freq) ile K1 keto formu (3_8S5_m1_1_K1) arasindaki tautomer denge değerlerini göstermektedir. $\mathrm{K}_{\mathrm{T} 2}$ tautomeri ise, enol formu (3_8S5_m1_1_E_freq) ile K2 keto formu (3_8S5_m1_1_K2) arasindaki tautomer denge değerlerini göstermektedir.
Molekülün enol formundaki (8S5_m1_1_E) H17'nin keto formuna (8S5_m1_1_K1) dönüşümünde N8'e bağlanması (proton göçü) ile ilgili enerji değişimi scan hesaplaması ile belirlenmiștir (Şekil 2). Dönüşüm esnasındaki bağ uzunlukları ve toplam enerjileri Tablo 4'de verilmiştir. $\mathrm{Bu}$ dönüşüm esnasında elde edilen scan grafiği Şekil 3'de verilmiştir (8scan_8S5_m1_1_E_Scan_016H17).

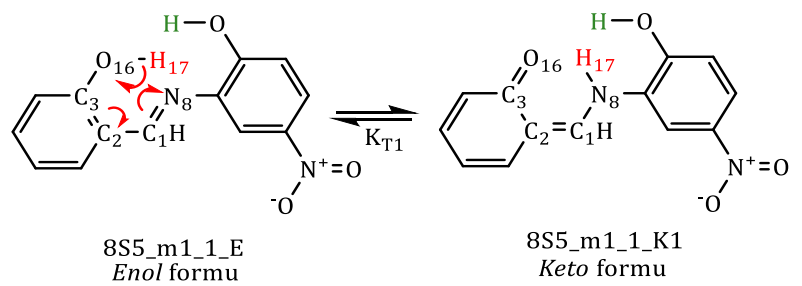

Şekil 2. Shiff bazı bileşiğindeki H17'nin $\mathrm{K}_{\mathrm{T} 1}$ tautomerlik dönüşümünde kayması

Tablo 3. Schiff bazı tautomerlerinin farklı çözücülerdeki enerjileri

\begin{tabular}{|c|c|c|c|c|c|c|c|}
\hline \multicolumn{6}{|c|}{ Molekül } & \multicolumn{2}{|c|}{ Tautomer } \\
\hline \multicolumn{2}{|c|}{ 3_8S5_m1_1_E_freq } & \multicolumn{2}{|c|}{ 2_8S5_m1_1_K1_freq } & \multicolumn{2}{|c|}{ 1_8S5_m1_1_K2_freq } & \multirow{2}{*}{ 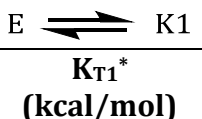 } & \multirow{2}{*}{ 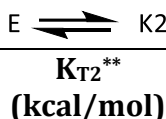 } \\
\hline Çözücü & $\begin{array}{c}\text { SETFE } \\
\text { (kcal/mol) }\end{array}$ & Çözücü & $\begin{array}{c}\text { SETFE } \\
\text { (kcal/mol) }\end{array}$ & Çözücü & $\begin{array}{c}\text { SETFE } \\
\text { (kcal/mol) }\end{array}$ & & \\
\hline$A S$ & $-572167,233$ & $A S$ & $-572160,946$ & $A S$ & $-572131,098$ & 6,287 & 36,135 \\
\hline$A S C N$ & $-572167,558$ & $A S C N$ & $-572161,245$ & $A S C N$ & $-572131,416$ & 6,313 & 36,142 \\
\hline $\mathrm{CHCl}_{3}$ & $-572165,129$ & CHCL3 & $-572158,735$ & $\mathrm{CHCl}_{3}$ & $-572128,751$ & 6,394 & 36,378 \\
\hline$D C M$ & $-572166,366$ & $D C M$ & $-572160,059$ & $D C M$ & $-572130,159$ & 6,307 & 36,207 \\
\hline$D M F$ & $-572165,659$ & $D M F$ & $-572159,307$ & $D M F$ & $-572129,355$ & 6,352 & 36,304 \\
\hline DMSO & $-572167,667$ & DMSO & $-572161,343$ & DMSO & $-572131,519$ & 6,324 & 36,148 \\
\hline ETOH & $-572167,366$ & ETOH & $-572161,066$ & ETOH & $-572131,229$ & 6,300 & 36,138 \\
\hline V & $-572157,321$ & V & $-572150,221$ & V & $-572119,648$ & 7,100 & 37,673 \\
\hline МЕТОН & $-572167,516$ & МЕTOH & $-572161,206$ & МЕTOH & $-572131,375$ & 6,310 & 36,140 \\
\hline
\end{tabular}


Tablo 4. Schiff bazı bileșiğinin $\mathrm{K}_{\mathrm{T} 1}$ tautomerlik dönüșümde değișen bazı parametreler ve değerleri

\begin{tabular}{|c|c|c|c|c|c|c|c|c|}
\hline \multirow{2}{*}{$\begin{array}{c}\text { Scan } \\
\text { Geometri } \\
\text { No } \\
\end{array}$} & \multirow{2}{*}{$\begin{array}{l}\text { Toplam enerji } \\
\text { (kcal/mol) }\end{array}$} & \multicolumn{6}{|c|}{ Molekülün değişen bağ uzunlukları ( $($ ) } & \multirow{2}{*}{ Scan geometri } \\
\hline & & 016-H17 & C3-016 & $\mathrm{C} 3-\mathrm{C} 2$ & $\mathrm{C} 2-\mathrm{C} 1$ & C1-N8 & N8-H17 & \\
\hline 1 & $-572263,960$ & 0,97 & 1,35 & 1,42 & 1,45 & 1,29 & 1,83 & \\
\hline 2 & $-572261,889$ & 1,07 & 1,34 & 1,42 & 1,44 & 1,30 & 1,62 & \\
\hline 3 & $-572257,671$ & 1,17 & 1,32 & 1,43 & 1,43 & 1,31 & 1,39 & \\
\hline 4 & $-572255,596$ & 1,27 & 1,30 & 1,45 & 1,42 & 1,35 & 1,22 & \\
\hline 5 & $-572255,309$ & 1,37 & 1,29 & 1,45 & 1,41 & 1,32 & 1,14 & \\
\hline 6 & $-572255,456$ & 1,47 & 1,28 & 1,468 & 1,40 & 1,33 & 1,09 & \\
\hline 7 & $-572255,523$ & 1,57 & 1,27 & 1,47 & 1,40 & 1,33 & 1,06 & \\
\hline 8 & $-572255,375$ & 1,67 & 1,27 & 1,47 & 1,39 & 1,34 & 1,05 & \\
\hline 9 & $-572254,930$ & 1,77 & 1,26 & 1,47 & 1,39 & 1,34 & 1,03 & \\
\hline 10 & $-572254,263$ & 1,88 & 1,26 & 1,48 & 1,39 & 1,34 & 1,03 & \\
\hline
\end{tabular}


Tablo 5. Schiff bazı bileșiğinin KT2 tautomerlik dönüșümde değișen bazı parametreler ve değerleri

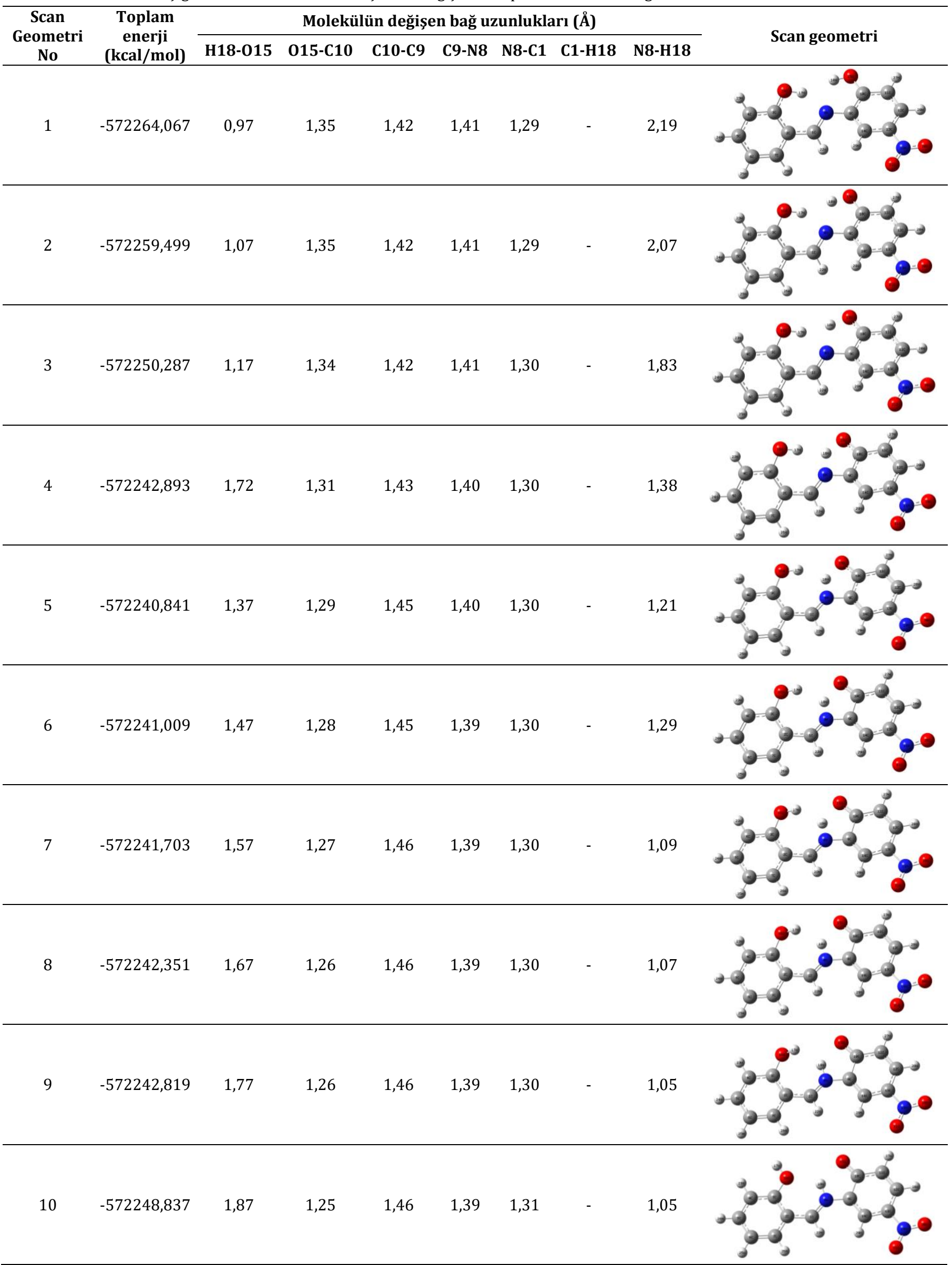




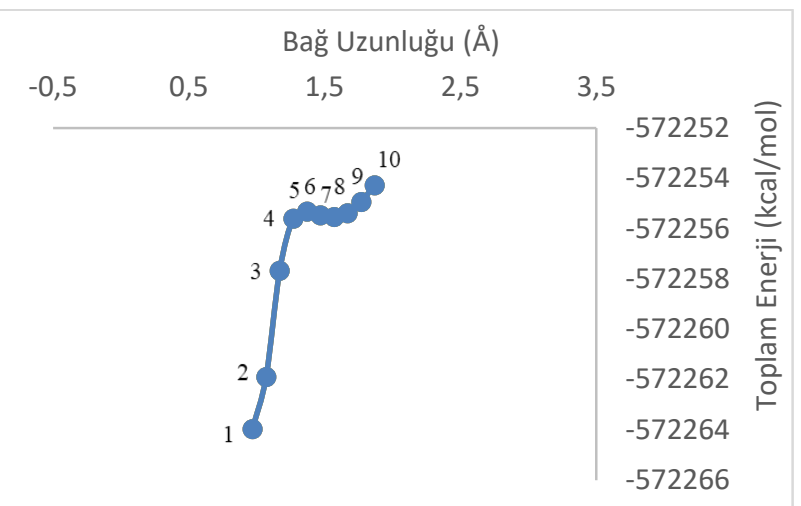

Șekil 3 Schiff bazı bileșiğinin $\mathrm{K}_{\mathrm{T} 1}$ tautomerlik dönüșümünde 016-H17 bağ uzunluğu-toplam enerji ilişkisi

Molekülün enol formundaki (8S5_m1_1_E) H18'nin keto formuna (8S5_m1_1_K2) dönüşümünde N8'e bağlanması ile ilgili enerji değişimi de scan hesaplaması ile belirlenmiştir (Şekil 4). Dönüşüm esnasındaki bağ uzunluğu ve toplam enerjileri Tablo 5 'de verilmiştir. Bu dönüşüm esnasında elde edilen scan grafiği de Şekil 5'de verilmiştir (9scan_8S5_m1_1_E_Scan_015H18).

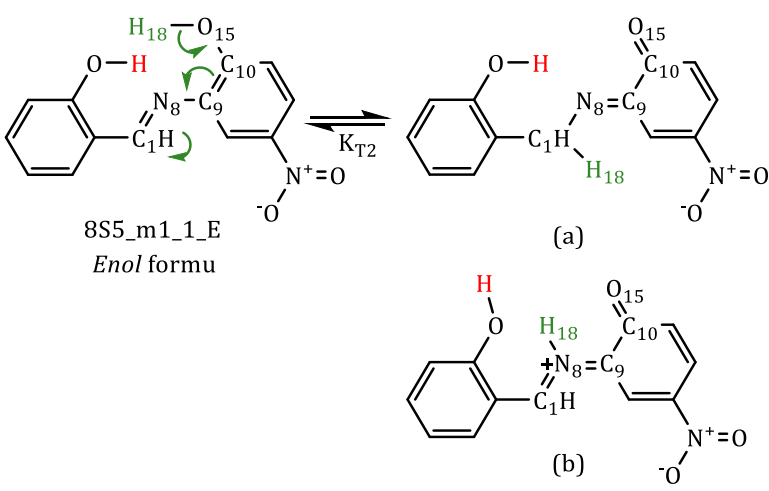

8S5_m1_1_K2

Keto formu

Şekil 4. Shiff bazı bileşiğindeki H18'nin KT2 tautomerlik dönüşümünde kayması (a) beklenen H18 kayması, (b) gözlenen H18 kayması

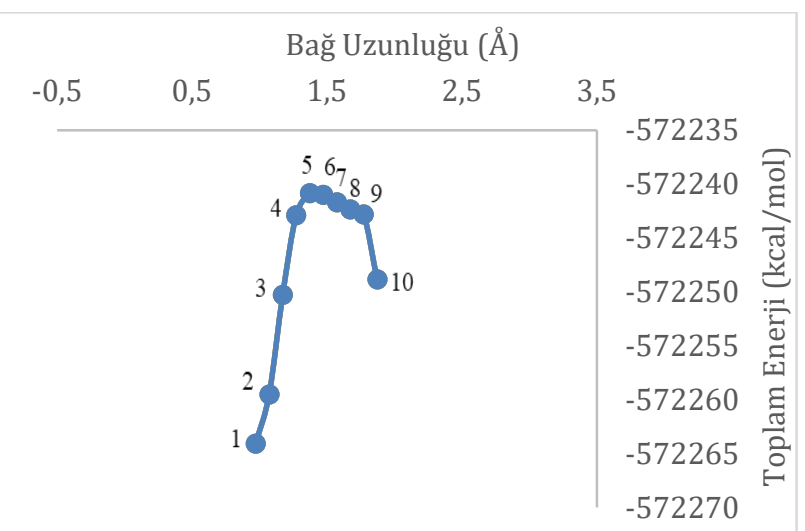

Şekil 5 Schiff bazı bileşiğinin $\mathrm{K}_{\mathrm{T} 2}$ tautomerlik dönüşümde H18- N8 bağ uzunluğu ve toplam enerji ilişkisi

Tautomer hesaplaması ile belirlenen kararlı enol formu (3_8S5_m1_1_E_freq) diğer hesaplamalarda da kullanılmıştır (UV-Vis., NBO, NMR, HOMO-LUMO, MEP ve SASA).

B3LYP metodu ve 6-311G++(d,p) temel seti ile vakumda frekans hesaplamasındaki geometriden belirlenen H-bağı değerleri Tablo 6'da verilmiștir. Molekül içi H-bağının molekülün kararlılığına etkisi büyüktür. Bu kararlılı enol ve keto formlarındaki tautomer dengesinde de görülmektedir (Tablo 6). Enol formunda iki güçlü H-bağı $(1,800$ (H17 ...N8) ve 2,192 (H18...N8)) ve keto formlarında ise bir güçlü H-bağı (K1:1,544 (H21...016) ve K2: 1,943 (H20......N8)) gözleniştir.

Tablo 6. Schiff bazı bileșiğinin tautomerlik dönüșümündeki hidrojen bağı analizi

$\left.\begin{array}{c}\text { Bağ uzunluğu } \\ (\AA)\end{array}\right)$

\subsection{NBO analizi}

Moleküldeki (3_8S5_m1_1_E) elektronca zengin ve elektronca yoksun merkezler atomik yüklerin hesaplanması ile belirlenmektedir. Elektronca zengin ya da yoksun atom ve merkezlerin bilinmesi reaksiyonlarda elektrofillerin veya nükleofillerin atak yapacağı merkezi bilmemize ve reaksiyon mekanizmasını anlamamıza yardımcı olmaktadır. Atomik yüklerin bilinmesinin bir diğer avantajı çözücü-çözünen arasındaki etkileşimi, molekül içi veya moleküller arası H-bağını tahmin etmemize olanak sağlamaktadır. Diğer taraftan bu sayede bazik ve asidik atomları da tahmin edilebilmektedir. Molekülün biyolojik aktif bir özelliğinin olması durumunda aktivitenin hangi atom veya fonksiyonel gruptan olacağı tahmin edilebilmektedir. Molekülün, 
kompleks reaksiyonlarda ligant olarak kullanılması durumunda ise koordine kovalent bağın hangi atomlar arasında olacağl anlaşılabilmektedir. NBO hesaplaması kararlı enol formu için B3LYP metodu ve 6-311G++(d,p) temel seti ile vakumda Gaussian NBO Version 3.1 ile yapılmıştır. Hesaplanan yükler Tablo 7'de verilmiştir. Bileşiğin, elektrofiller, elektrofilik merkezler ve asitler (protik veya Lewis) ile etkinleşecek elektronca en zengin (nükleofilik) merkezleri $016(-0,675), 015(-0,651)$ ve N8 $(-0,574)$ atomlarıdır. Bileşiğin nükleofiller, nükleofilik merkezler ve bazlar (hidroksi veya Lewis) ile etkinleşecek elektronca en zaylf (elektrofilik) merkezleri H17 $(0,500)$ ve H18 $(0,487)$ atomlarıdır.

Tablo 7. Schiff bazı bileșiğinin doğal atomik yükleri (NBO)

\begin{tabular}{|c|c|c|c|}
\hline $\mathrm{H}_{24}$ & $\begin{array}{l}\mathrm{O}_{23} \\
\mathrm{C}_{4}-\mathrm{C}_{3} \\
\mathrm{C}_{5} \mathrm{C}_{2}-\end{array}$ & 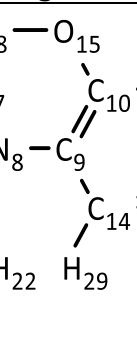 & $\begin{array}{l}{ }^{\prime} \mathrm{C}_{12}-\mathrm{H}_{28} \\
\mathrm{~N}_{19}{ }^{+} \mathrm{O}_{20} \\
{ }_{21}\end{array}$ \\
\hline Atom no & Doğal yük* & Atom no & Doğal yük* \\
\hline C1 & 0,178 & 016 & $-0,675$ \\
\hline $\mathrm{C} 2$ & $-0,198$ & H17 & 0,500 \\
\hline C3 & 0,380 & H18 & 0,487 \\
\hline $\mathrm{C} 4$ & $-0,254$ & N19 & 0,484 \\
\hline C5 & $-0,148$ & 020 & $-0,384$ \\
\hline C6 & $-0,240$ & 021 & $-0,393$ \\
\hline $\mathrm{C} 7$ & $-0,139$ & $\mathrm{H} 22$ & 0,173 \\
\hline N8 & $-0,574$ & H23 & 0,223 \\
\hline C9 & 0,081 & $\mathrm{H} 24$ & 0,210 \\
\hline C10 & 0,354 & $\mathrm{H} 25$ & 0,212 \\
\hline C11 & $-0,240$ & $\mathrm{H} 26$ & 0,207 \\
\hline $\mathrm{C} 12$ & $-0,167$ & $\mathrm{H} 27$ & 0,228 \\
\hline C13 & 0,051 & $\mathrm{H} 28$ & 0,244 \\
\hline $\mathrm{C} 14$ & $-0,194$ & $\mathrm{H} 29$ & 0,244 \\
\hline 015 & $-0,651$ & & \\
\hline
\end{tabular}

* Negatif yük değerleri elektronca zengin, pozitif yük değerleri ise elektronca yoksun olduğu anlamina gelmektedir.

\subsection{IR spektrum analizi}

Molekülün teorik olarak IR spektrumunun çizdirilmesi ve frekans değerlerinin bilinmesi, moleküldeki fonksiyonel grupları açıklamak için önemlidir. Özellikle deneysel IR spektrumunda açıklanamayan bazı piklerin, teorik olarak molekülün geometrisinde değişiklikler yapılarak hesaplama ile açıklanabilmektedir. Ayrıca teorik hesaplama ile belirlenen IR frekans değerlerinden, deneysel ortamdaki molekülün geometrisi veya geometrileri tahmin edilebilmektedir. Molekülün (3_8S5_m1_1_E) B3LYP metodu ve 6-311G++(d,p) temel seti ile yapilan frekans hesaplaması sonucunda elde edilen ve Excel programında çizdirilen IR grafiği Şekil 6'da ve seçilmiş titreşim frekans değerleri ise Tablo 8'da verilmiştir. Bileşiğin sentezlendiğini kanıtlayan en belirgin fonksiyonel grup $\mathrm{HC}=\mathrm{N}$ grubudur ve literatürde gözlenmesi gereken frekans değerinde hesaplandığ gözlendi $\left(1642,30 \mathrm{~cm}^{-1}\right)$. Bileşiğin varlığını kanıtlayan diğer pikler ise literatür değerlerine uygun hesaplandı̆̆ı gözlendi.

\subsection{NMR spektrum analizi}

Teorik NMR ile hesaplanan kimyasal kayma değerlerinin önceden bilinmesi, deneysel NMR kimyasal kayma değerlerini açlklamakta yardımcı olmaktadır. Ayrıca deneysel olarak açıklanamayan bazı kimyasal kayma değerleri teorik hesaplama ile açılkanabilmektedir. Molekülün (3_8S5_m1_1_E) B3LYP metodu ve 6-311G++(d,p) temel seti ile yapilan NMR (DMSO) hesaplaması sonucunda elde edilen kimyasal kayma (ppm) değerleri Tablo 9'da verilmiştir. NMR spektroskopisinde bileşiğin sentezlendiğini kanıtlayan en belirgin kimyasal kayma değeri $\mathrm{HC}=\mathrm{N}$ grubundaki kimyasal kayma değeridir ve literatürde gözlenmesi gereken ppm değerinde hesaplandığı gözlendi $(22 \mathrm{H}: 8,970$ ve $1 \mathrm{C}: 172,920$ ppm). Bileşiğin varlığını kanıtlayan diğer kimyasal kayma değerleri ise literatür değerlerine uygun hesaplandığı gözlendi.

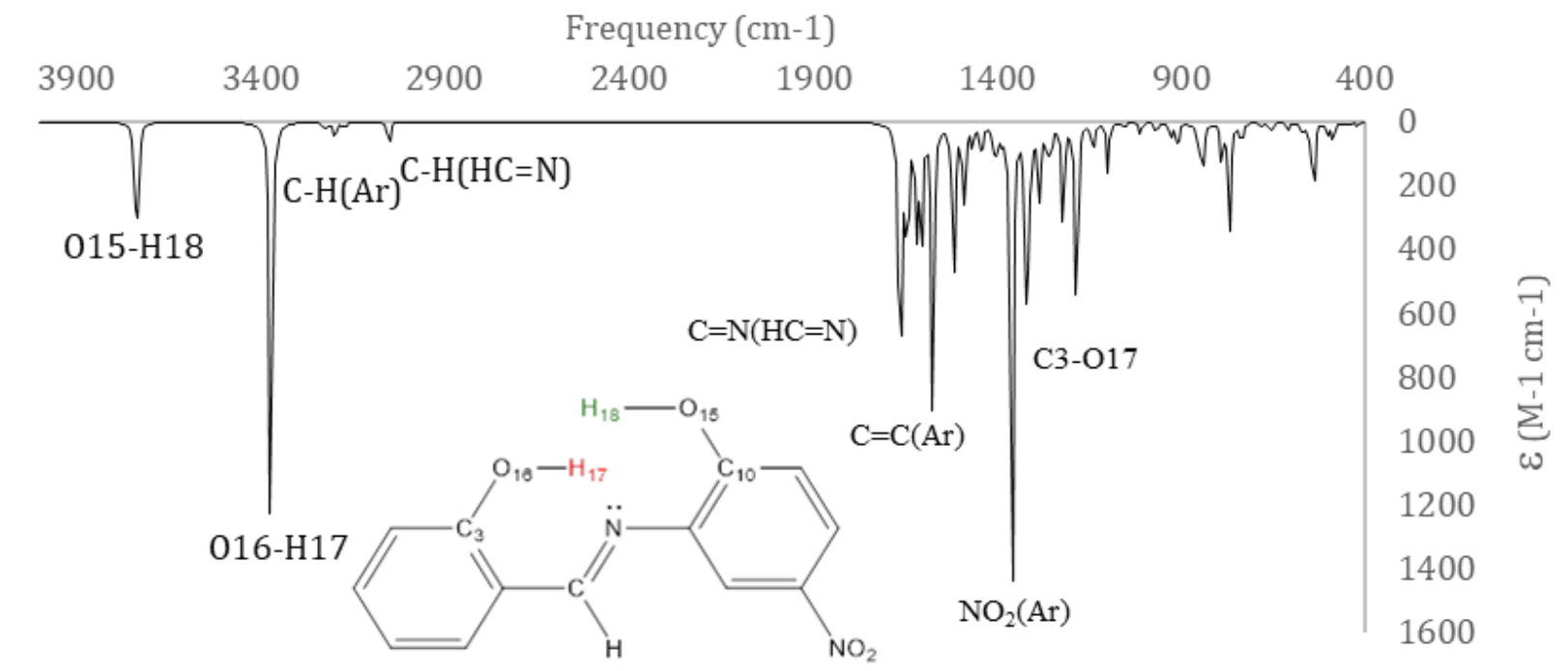

Şekil 6. Schiff bazı bileșiğinin teorik IR spektrumu 
Tablo 8. Schiff bazı bileşiğinin seçilmiș teorik IR spektrum verileri $\left(v \mathrm{~cm}^{-1}\right)$

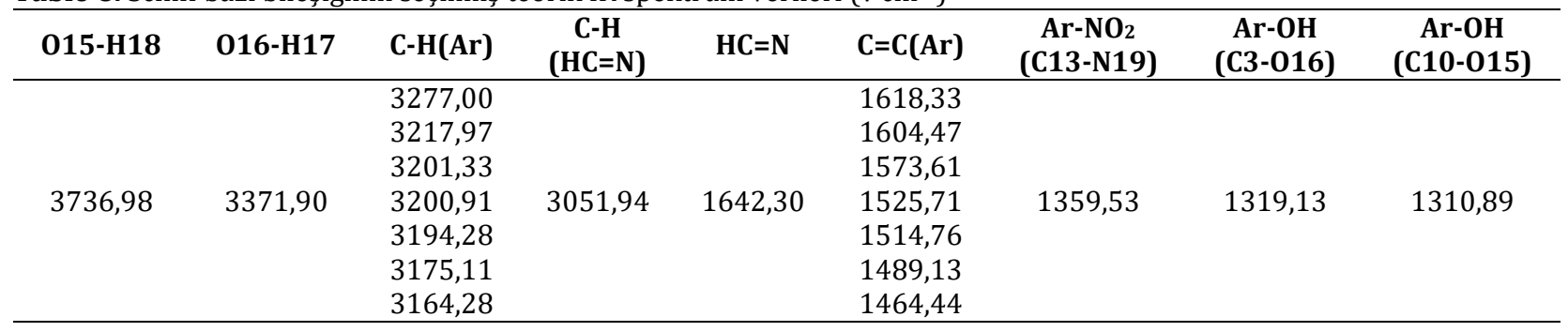

Tablo 9. Çalışllan molekülün ${ }^{13} \mathrm{C}$ ve ${ }^{1} \mathrm{H}$ NMR kimyasal kayma değerleri

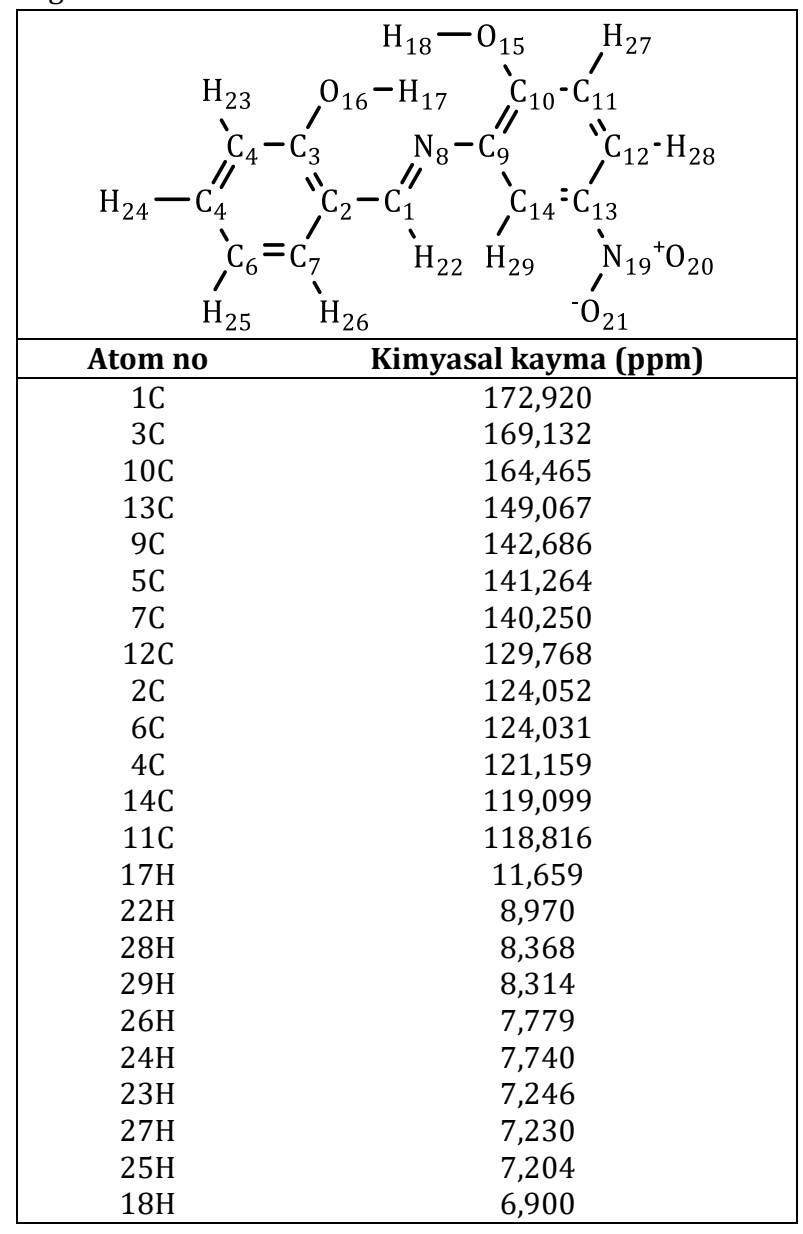

\subsection{UV spektrum analizi}

Teorik olarak UV-Vis. hesaplamalarından molekülün vakum ve çözücü fazlarında dalga boyu $\left(\lambda_{\max }\right)$, değerleri ve çözücü-çözünen etkileşimleri tahmin edilebilmektedir. Önceden sentezi gerçekleștirilmemiș bir molekülün istenen dalga boyuna $\left(\lambda_{\max }\right)$ ait molekül, hesaplamalar ile tasarlanabilir ve daha sonra sentezi gerçekleștirilebilir. Bu ve buna benzer veriler önceden teorik hesaplama ile tahmin edilebilmektedir. Molekülün (3_8S5_m1_1_E) TD-SCF B3LYP metodu ve 6-311G++(d,p) temel seti ile yapılan UV-Vis. hesaplaması sonucunda elde edilen veriler kullanılarak Excel programında UV-Vis. spektrumu çizilmiştir ve Şekil 7'de verilmiştir. Bu grafikten okunan dalga boyu $\left(\lambda_{\max }\right)$ değerleri ise Tablo $10^{\prime}$ de verilmiştir.

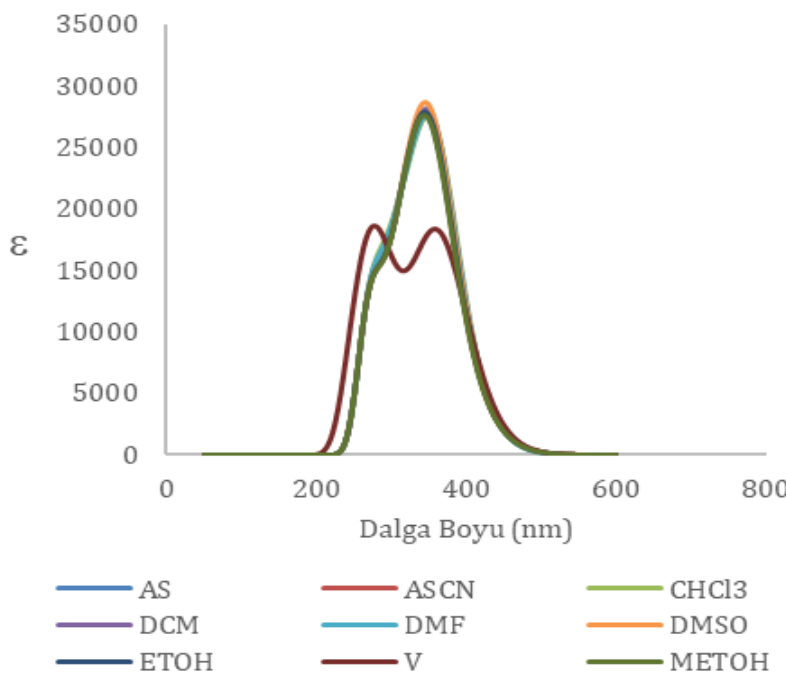

Şekil 7. Çalıșılan molekülün vakum ve farklı çözücülerdeki UV-Vis. spektrumları

Tablo 10. Schiff bazı bileşiğinin vakum ve farklı çözücülerdeki $\lambda_{\max }$ değerleri

\begin{tabular}{|c|c|c|c|c|}
\hline \multirow{2}{*}{ Molekül } & \multicolumn{2}{|c|}{ Teorik UV-Vis. (nm) } & \multirow{2}{*}{$\Delta \lambda_{1 \max }$} & \multirow{2}{*}{$\Delta \lambda_{2 \max }$} \\
\hline & $\lambda_{1 \max }$ & $\lambda_{2 \max }$ & & \\
\hline DMSO & 275,5 & 348,1 & 4,4 & 12,1 \\
\hline$A S C N$ & 278,8 & 344,8 & 1,1 & 15,4 \\
\hline$D M F$ & 277,8 & 348,1 & 2,1 & 12,1 \\
\hline МЕТОН & 278,8 & 343,7 & 1,1 & 16,5 \\
\hline ЕТОН & 278,8 & 348,8 & 1,1 & 11,4 \\
\hline$A S$ & 279,9 & 344,8 & 0,0 & 15,4 \\
\hline$D C M$ & 277,7 & 348,1 & 2,2 & 12,1 \\
\hline $\mathrm{CHCl}_{3}$ & 278,8 & 349,2 & 1,1 & 11,0 \\
\hline V & 279,9 & 360,2 & 0,0 & 0,0 \\
\hline
\end{tabular}

$\Delta \lambda_{1 \text { max }}=\lambda_{1 \text { Vakum }}-\lambda_{1 \text { Çözücü; }} \Delta \lambda_{2 \max }=\lambda_{2 \text { Vakum }}-\lambda_{2 \text { Çözücü }}$

Tablo 10 ve Şekil 7'de 343,7-360,2 $\mathrm{nm}\left(\lambda_{2 \max }\right)$ dalga boyuna ait elektronik geçişlerin $n-\pi^{*}$ geçişlerine, spektrumda omuz olarak görünen $(275,5-279,9 \mathrm{~nm}$ $\left(\lambda_{1 \max }\right)$ dalga boyuna ait elektronik geçişlerin ise $\pi-\pi^{*}$ geçişlerine ait olması söz konusudur. Bileşiğin çözücüçözünen etkileşimi belirlemek için, vakum ile çözücü arasındaki kimyasal kayma değerleri hesaplandı $\left(\Delta \lambda_{1 \max } \quad\right.$ ve $\left.\Delta \lambda_{2 \max }\right) . \quad \pi-\pi^{*}$ elektronik geçişlerinin çözücülerden neredeyse hiç etkilenmediği $\Delta \lambda_{1 \max }(1,1-$ $4,4)$ değerlerinden anlaşılmaktadır. $n-\pi^{*}$ elektronik geçişlerinin ise çözücülerden etkilendiği $\Delta \lambda_{2 \max }(11,0-$ 16,5) değerlerinden anlaşılmaktadır. 


\subsection{Kuantum kimyasal parametrelerin hesaplanması (dipol moment, HOMO ve LUMO)}

Dipol moment değeri, moleküldeki yük dağılımı hakkında bilgi verir. Ayrıca dipol momentin yüksek olması yük dağılımının, moleküldeki farklı atom, grup ya da bölgelerde yoğun olması, düşük olması ise az olduğunu anlamına gelmektedir. Dipol moment aynı zamanda çözücü-çözünen etkileşimini de anlamamıza yardımcı olmaktadır. B3LYP metodu ve 6$311 \mathrm{G}++(\mathrm{d}, \mathrm{p})$ temel seti ile vakumda frekans hesaplamasındaki dipol moment değerleri Tablo 11 'de verilmiştir. Bileșiğin enol formunda yüksek $(5,078-6,141)$ ve keto formlarında ise düşük (K1:3,302-3,612; K2:1,609-2,958) dipol moment değerleri gözlenmiştir. Bu sonuçlar bileşiğin enol formunun polar ve keto formlarının ise daha düşük polar karaktere sahip olduğunu göstermektedir.

Tablo 11. Schiff bazı bileșiğin dipol moment değerler

\begin{tabular}{|c|c|c|c|c|c|}
\hline \multicolumn{6}{|c|}{ Molekül } \\
\hline \multirow{2}{*}{\multicolumn{2}{|c|}{$\begin{array}{c}\text { 3_8S5_m1_1_E } \\
\begin{array}{c}\text { Dipol moment } \\
\text { (Debye) }\end{array}\end{array}$}} & \multirow{2}{*}{\multicolumn{2}{|c|}{$\begin{array}{c}\text { 2_8S5_m1_1_K1 } \\
\begin{array}{c}\text { Dipol moment } \\
\text { (Debye) }\end{array}\end{array}$}} & \multirow{2}{*}{\multicolumn{2}{|c|}{$\begin{array}{c}\text { 1_8S5_m1_1_K2 } \\
\begin{array}{c}\text { Dipol moment } \\
\text { (Debye) }\end{array}\end{array}$}} \\
\hline & & & & & \\
\hline$A S$ & 6,103 & $A S$ & 3,602 & $A S$ & 2,901 \\
\hline$A S C N$ & 6,132 & $A S C N$ & 3,609 & $A S C N$ & 2,944 \\
\hline $\mathrm{CHCl}_{3}$ & 5,887 & $\mathrm{CHCl}_{3}$ & 3,545 & $\mathrm{CHCl}_{3}$ & 2,591 \\
\hline$D C M$ & 6,016 & $D C M$ & 3,579 & $D C M$ & 2,775 \\
\hline$D M F$ & 5,943 & $D M F$ & 3,560 & $D M F$ & 2,670 \\
\hline DMSO & 6,141 & DMSO & 3,612 & DMSO & 2,958 \\
\hline ETOH & 6,115 & ETOH & 3,605 & ETOH & 2,919 \\
\hline V & 5,078 & V & 3,302 & V & 1,609 \\
\hline МЕТОН & 6,128 & МЕТОН & 3,608 & МЕТОН & 2,939 \\
\hline
\end{tabular}

HOMO, LUMO ve HOMO-LUMO arasındaki enerji boşluğu $\left(E_{G A P}\right)$ moleküllerin kimyasal davranışlarını ve reaktivitesini açılamaya yardımcı olur. Reaksiyonlarda, nükleofilin HOMO'su ile elektrofilin LUMO'su reaksiyona girer. $E_{G A P}$ değerinin sayısal olarak büyük veya küçük olması reaksiyonun mekanizmasını ve reaksiyon koşullarını belirlemektedir.

$E_{G A P}$ değerinin sayısal olarak büyük veya küçük olması görünür bölgedeki molekülün rengini tahmin edebilmek için önemlidir. $E_{G A P}$ değerinin sayısal olarak küçük olması konjugasyon göstermekte ve daha düşük enerjide uyarılmasına neden olmaktadır. $E_{G A P}$ değerinin sayısal olarak yüksek olması ise konjugasyon olasılığı çok daha az olmakta ve daha yüksel enerjide uyarılmasına neden olmaktadır.

Düşük enerjili $E_{G A P}$ değerlerine sahip moleküller düşük enerjiler tarafından uyarılabildiklerinden, sıklıkla bazı ilginç optik özellikler gösterirler. Ayrıca molekül içi elektron transferi (çözeltide) ve metalik iletkenlik (katı halde) gibi elektronik özellik gösterirler.

$E_{G A P}$ değerleri sıfıra yaklaşan moleküller genellikle yüksek oranda konjugasyona sahip özelliklerinden dolayı Güneş pili malzemeleri olarak kullanılmaktadır. $\mathrm{Bu}$ ve buna benzer özelliklerden dolayı HOMO, LUMO ve $E_{G A P}$ enerji değerlerinin önceden bilinmesi molekülün özelliklerinin tahmin edilebilmesi açısından önemlidir. DFT TD-SCF B3LYP metodu ve 6$311 \mathrm{G}++(\mathrm{d}, \mathrm{p})$ temel seti ile yapılan hesaplama ile belirlenen HOMO, LUMO ve $E_{G A P}$ enerji değerleri ve şekilleri Tablo 12'de verilmiştir.

Hesaplanan $\Delta E_{G A P}, \quad 2,691 \mathrm{eV}$ değeri, bileşiğin reaksiyonlarda reaktif olması, metaller için iyi bir ligand, iletken özellikler göstermesi, konjugasyona sahip ve renkli bileşik olması anlamına gelmekte ve bu alanlar için aday bileşik olması anlamına gelmektedir.

Tablo 12. Schiff bazı bileşiğine ait HOMO, LUMO değerleri ve bant aralığı enerjileri

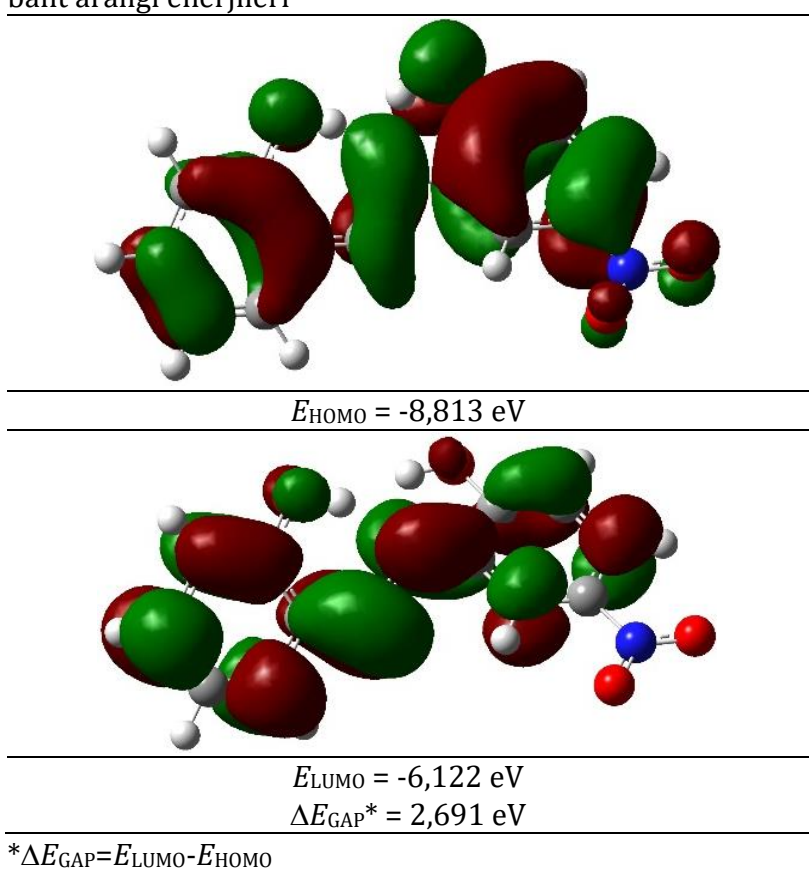

\subsection{MEP yüzey analizi}

Moleküler elektrostatik potansiyel enerji haritaları, moleküllerin yük dağılımlarını üç boyutlu olarak ve molekülün yüklü bölgelerini görsel olarak görmemize imkân sağlar. Moleküllerin birbirleriyle nasıl etkileștiğini belirlemek için yük dağılımları bilgisi önemlidir. Ayrıca dipol moment, elektronegatiflik ve kısmi yükler ile ilgili görsel bilgiler verir ve bir molekülün polaritesi tahmin edilebilir. DFT B3LYP metodu ve 6-311G++(d,p) temel seti ile hesaplanan MEP haritası Şekil 8'de verilmiştir.

MEP haritasından bileşiğin elektrofiller ve nükleofiller ile reaksiyon verecek merkezlerinin olduğunu $(-\mathrm{OH}$ ve $\mathrm{CH}=\mathrm{N}$ ), $-\mathrm{OH}$ ve $-\mathrm{NO}_{2}$ gruplarından dolayı polarlaşmaya neden olması yük dağılımının eşit olmadığı ve polar merkezlerin oluşması ile bileşiğin polar ve yüksek dipole sahip olması anlamına gelmektedir. Çözücüçözünen etkileşiminde polar ve polar protik çözücüleri tercih etmesi, moleküller arası etkileşimlerde H-bağı yapabilecek merkezlerin olması biyolojik sistemler açısından da biyolojik aktiviteye sahip aday olması söz konusudur. 


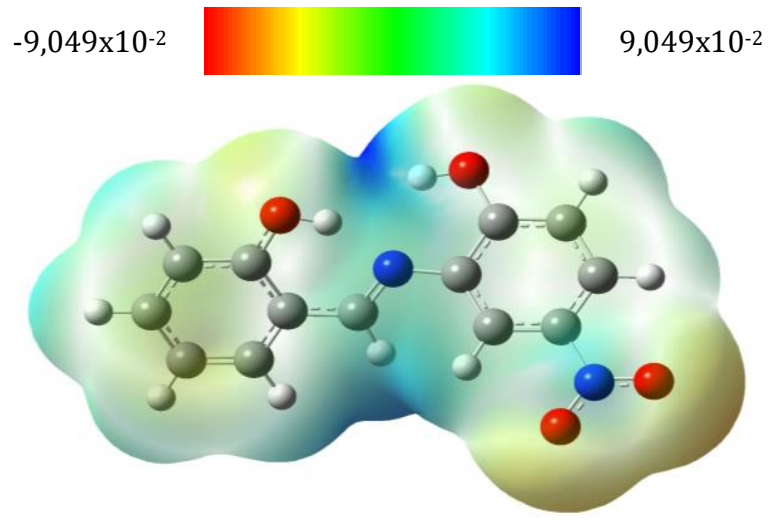

Şekil 8. Schiff bazı bileşiğinin moleküler elektrostatik potansiyel (MEP)

\subsection{SASA yüzey analizi}

SASA (çözücü erişilebilirlik yüzey alanı; solvent accessible surface area), çözücü ortamında çözünmüş veya çözünecek bir molekülün çözücü molekülü ile nasıl etkileșime girdiğini görmemize yardımcı olan bir görseldir. Çözücü-çözünen etkileşimi dişında biyolojik sistemlerde de molekülün biyolojik sistemle etkileșme derecesini anlamak için önemlidir. DFT B3LYP metodu ve $6-311 \mathrm{G}++(\mathrm{d}, \mathrm{p})$ temel seti ile hesaplanan SASA haritası Şekil 9'da verilmiştir.

SASA haritası, polar ve polar protik çözücülerin bileşikteki $-\mathrm{OH},-\mathrm{NO}_{2}$ ve imin azotu $(\mathrm{CH}=\mathrm{N})$ ile, apolar çözücülerin ise aromatik halkadaki $C$ ve H'ler ile etkileşeceği anlamına gelmektedir. Özellikle biyolojik sistemlerde de bu merkezler ile aktivite göstereceği anlaşılmaktadır.

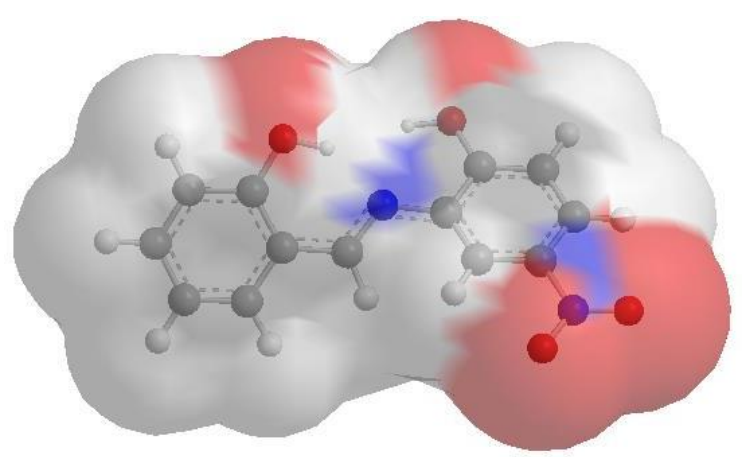

Şekil 9. Schiff bazı bileşiğinin çözücü erişilebilirlik yüzey alanı (SASA)

\section{Tartışma ve Sonuç}

Çalışılan molekülün tüm konformasyon hesaplamaları sonunda Ek E; Ek F ve Ek G'de ayrıntıları verilen 3_8S5_m1_1_E_opt, 2_8S5_m1_1_K1_opt ve 1_8S5_m1_1_K2_opt konformasyonlarının en kararlı konformasyonlar olduğu belirlenmiștir (Tablo 2). Hesaplamalarda bu konformasyonlar kullanılmıştır.

Tablo 3'deki, bu çalışma kapsamındaki molekülün ve olası tautomer formlarının farklı çözücülerdeki hesaplamaları incelendiğinde; $\mathrm{K}_{\mathrm{T} 1} \quad$ tautomer değerlerinin vakum ve tüm çözücülerde pozitif sayısal değerlerinde olması (yaklaşık 6-7), enol tautomer formlarının kararlı olduğu, dengenin enol formuna doğru olduğu anlaşılmaktadır. $\mathrm{K}_{\mathrm{T} 1}$ tautomer dengesinde sayısal değerlerin 6-7 kcal/mol arasında bir değere sahip olması her iki tautomer arasında büyük enerji farkı olmadığını göstermektedir. Enol tautomer formundaki molekülün keto tautomer formuna dönmesi değişimindeki enerji değişiminin çok az olması, değişen reaksiyon koşullarında (çözücü, sıcaklık ve basınç gibi) iki tautomer formununda reaksiyon ortamında bulunabileceği anlamına gelmektedir. $\mathrm{K}_{\mathrm{T} 2}$ tautomer değerlerinin tüm fazlarda pozitif ve sayısal değerlerinin de yüksek olması (36-37 $\mathrm{kcal} / \mathrm{mol}$ ), bu tautomer form için de enol tautomer formlarının kararlı olduğu, dengenin enol formuna doğru olduğu anlaşılmaktadır. $\mathrm{K}_{\mathrm{T} 2}$ tautomer dengesinde sayısal değerlerin tüm fazlar için yaklaşık $36 \mathrm{kcal} / \mathrm{mol}$ gibi bir değere sahip olması her iki tautomer arasında büyük enerji farkı olmadığını göstermektedir. $\mathrm{Bu}$ sonuçlardan, $\mathrm{K}_{\mathrm{T} 2}$ tautomer formunun reaksiyon ortamında oluşma olasılığının düşük ihtimal olduğu anlamına gelmektedir.

Molekülün enol formundaki (8S5_m1_1_E) H17'nin keto formuna (8S5_m1_1_K1) dönüșümünde N8'e bağlanması (proton transferi) ile ilgili enerji değișimine ait hesaplamalar (Şekil 2, Tablo 4 ve Şekil 3) incelendiğinde 2.scan geometride $-572261,889$ $\mathrm{kcal} / \mathrm{mol}$ enerjisinde 016'ya bağlı hidrojenin (H17) $1,07 \AA ̊$ bağ uzunluğunda koptuğu ve C3 ve 016 arasında $1,34 \AA$ bağ uzunluğunda ise karbonil oluşmaya başladığı görülmektedir. Şekil 3 incelendiğinde H17 hidrojeninin kopması sürecinde enerjinin 4.scan geometrisine kadar yükseldiği N8 bağlanma süreci başladığında ise düşmeye başladığı görülmektedir. 6.Scan geometride karbonilin oluştuğu (keto formu) ve 8.scan geometride ise H17'nin N8 bağlandığı görülmektedir. Keto formunun oluştuğu andaki (8.scan geometri) enerji $-572255,375 \mathrm{kcal} / \mathrm{mol}$ karbonil bağ uzunluğu (C3-016) 1,27 ̊ ve protonun göçtüğü N-H bağ uzunluğu ise N8-H17 1,05 olarak yeniden düzenlendiği görülmektedir. Hidrojenin (H17) beklenildiği gibi oksijenden koparak (016) bağ oluşumunda kullanılmayan elektronlara sahip elektronca zengin azota (N8) göçtüğü gözlenmiştir.

Molekülün enol formundaki (8S5_m1_1_E) H18'nin keto formuna (8S5_m1_1_K2) dönüşümünde N8'e bağlanması (proton göçü) ile ilgili enerji değiş̧imine ait hesaplamalar (Şekil 4, Tablo 5 ve Şekil 5) incelendiğinde H18'in rezonans formda bağlanması gereken C1 atomuna (Şekil 4. (a)) göçmediği N8 atomuna (Şekil 4. (b)) göçtüğü gözlenmiştir. Protonun (H18) elektro zaylf bir karbon atomuna (C1) bağlanmayı tercih etmeyeceği tam tersine elektronca zengin olan bağ oluşumunda da kullanılmayan elektronlara sahip azota göçmeyi tercih ettiği gözlenmiştir. Bu durumdan dolayı $\mathrm{K} 2$ tautomer formu kararlı olmamaktadır. H18 hidrojeninin olası bir 
tautomer formunda azot atomuna (N8) bağlanacağı sonucuna varılmaktadır. H18'in oksijen atomunun 2.scan geometride koptuğu enerji 572259,499 $\mathrm{kcal} / \mathrm{mol}$ ve 015-H18 bağ uzunluğu $1,07 \AA$ olarak gözlenmiştir. 6.Scan geometride karbonilin (015-C10) oluştuğu ve bu geometrideki enerjinin $-572241,009$ $\mathrm{kcal} / \mathrm{mol}$ ile bağ uzunluğunun ise $1,28 \AA$ olduğu gözlenmiştir. Bu süreçteki enerji değişimi Şekil 5'ten görülmektedir. H18 hidrojenin azota bağlanma sürecinde enerji düşüşü gözlenmiş ve 9.scan geometride protonun (H18) azota göçtüğü enerji $572242,819 \mathrm{kcal} / \mathrm{mol}$ N8-H18 bağ uzunluğunun $1,05 \AA$ karbonil (C10-015) bağ uzunluğu ise 1,26 ̊ olduğunda keto formuna döndüğü gözlenmiştir.

B3LYP metodu ve 6-311G++(d,p) temel seti ile vakumda frekans hesaplamasındaki geometriden belirlenen en kararlı enol formunun (3_8S5_m1_1_E_freq) H-bağı değerleri incelendiğinde; 3_8S5_m1_1_E_freq_g enol tautomerinde H17......N8 arasında güçlü $(1,800)$ ve H18.......N8 $(2,192)$ arasında ise daha az güçlü H-bağı bağlarına sahip olduğu, H17.....O15 $(3,294)$ ve H18.....016 $(3,231)$ 'de ise daha zayıf bir olası H-bağı olduğu söylenebilir. 3_8S5_m1_1_K1_freq_g keto tautomerinde aromatik halkanın bozulmuş olmasına rağmen güçlü molekül için H-bağlarından (H21......016: 1,544; H21.....015: 2,624; H20......016: 2,726; H20......N8:2,373) dolayı kararlı bir tautomer form ( $\mathrm{K}_{\mathrm{T} 1}$ yaklaşık 6-7) olarak davrandığı görülmektedir. $\mathrm{K}_{\mathrm{T} 2}$ tautomer formunun kararsız olması yine zayıf molekül içi H-bağlarından H20 ......N8 (1,943); H20......015 $(3,062)$ kaynaklandığı söylenebilir (Tablo 6).

Moleküldeki (3_8S5_m1_1_E) NBO (Natural Bond Orbital) hesaplamalarından doğal atomik yükler incelendiğinde; C2-C7 karbon atomlarının bulunduğu aromatik halkanın C9-C14 karbon atomların bulunduğu aromatik halkadaki atom yüklerine göre daha fazla elektronca zengin (daha düşük negatif değerlere sahip) olduğu görülmektedir (Tablo 7), C2C7 karbon atomlarının yüklerinin daha fazla olması 016 atomunun mezomerik olarak halkaya elektron itmesinden kaynaklanmaktadır. C9-C14 karbon atomların bulunduğu aromatik halkada 015 atomu mezomerik olarak elektron iterken $\mathrm{NO}_{2}$ grubu ise elektron çekmektedir. $\mathrm{Bu}$ durum da aromatik halkadaki atomların yüklerinin daha az olmasına neden olmaktadır (Tablo 7). Tüm hidrojenler arasında en az elektron içeren yani en elektronca yoksun (daha yüksek pozitif değere sahip) hidrojenler H17 $(0,500)$ ve H18 $(0,487)$ hidrojenleridir. Daha yüksek pozitif değere sahip hidrojenler genellikle asidik hidrojenlerdir. $\mathrm{Bu}$ sonuçlara göre en asidik iki hidrojenin H17 ve H18 hidrojenlerinin olduğu ve bunların içerisinde ise en asidik olanın ise H17 olduğu sonucuna varılır. MOPAC2016 paket programında [32] PM6 metodu ile teorik $\mathrm{pK}_{\mathrm{a}}$ hesaplaması yapılmıştır ( $\mathrm{H} 17 ; \mathrm{pK}_{\mathrm{a}}=05,946$ ve $\left.\mathrm{H} 18 ; \mathrm{pK}_{\mathrm{a}}=07,741\right)$ ve NBO ile olası asidik olarak belirlenen hidrojenlerin asitlikleri ile uyumlu olduğu gözlenmiştir (Tablo 7).
Molekülün (3_8S5_m1_1_E) B3LYP metodu ve 6$311 \mathrm{G}++(\mathrm{d}, \mathrm{p})$ temel seti ile yapılan frekans hesaplaması sonucunda elde edilen teorik IR verilerinden $\mathrm{O}-\mathrm{H}$ pikleri iki ayrı pik olarak geldiği Şekil 6'da görülmektedir. O-H piklerinden; 015-H18; $3736,98 \mathrm{~cm}^{-1}$ de $016-\mathrm{H} 17$ ise $3371,90 \mathrm{~cm}^{-1}$ de iki keskin pik olarak gözlenmiștir. Aromatik halkadaki C$\mathrm{H}$ pikleri ise beklenildiği gibi 3164-3277 $\mathrm{cm}^{-1}{ }^{\prime} \mathrm{de}$ gözlenmiştir. Özellikle bu bileşiğin sentezlendiğini kanıtlayan $\mathrm{HC}=\mathrm{N}$ piki yine beklenildiği gibi $1642 \mathrm{~cm}^{-}$ ${ }^{1}$ 'de gözlenmiştir. Ayrıca, Ar- $\mathrm{NO}_{2}$ (C13-N19) ait pik $1359,53 \mathrm{~cm}^{-1}$, Ar-OH (C3-016) ait pik 1319,13 cm-1 ve Ar-OH (C10-015) $\mathrm{cm}^{-1}$ 'de geldiği görülmüștür (Tablo 8; Şekil 6). Teorik olarak hesapla belirlenen fonksiyonel gruplara ait IR frekans değerlerinin literatür değerleri ile uyumlu olduğu ve bu sonuçlara göre de yapının doğruluğunu kanıtlandığı sonucuna varllabilir [33-35].

Molekülün (3_8S5_m1_1_E) B3LYP metodu ve 6$311 \mathrm{G}++(\mathrm{d}, \mathrm{p})$ temel seti ile yapilan NMR (DMSO) hesaplamasından elde edilen kimyasal kayma (ppm) değerlerinden; molekülün (3_8S5_m1_1_E) yapısında 13 karbon ve 10 hidrojen bulunmaktadır $\left(\mathrm{C}_{13} \mathrm{H}_{10} \mathrm{~N}_{2} \mathrm{O}_{4}\right)$. Hesaplama sonunda tüm karbon $\left({ }^{13} \mathrm{C}\right)$ ve hidrojenlere $\left({ }^{1} \mathrm{H}\right)$ ait pikler gözlenmiştir. Molekülün sentezlendiğini kanttlayan imin $(\mathrm{HC}=\mathrm{N})$ grubundaki hidrojenin $1 \mathrm{H}$ pikinin kimyasal kayma değeri $(22 \mathrm{H}$ : $8,970 \mathrm{ppm}$ ) literatürdeki değerler ile uyumlu olarak gelmiștir. $18 \mathrm{H}$ ait $1 \mathrm{H}$ pikinin $(18 \mathrm{H}: 6,900)$ ise $17 \mathrm{H}$ pikine yakın (17H: 11,659) gelmesi beklenirken farklı geldiği gözlenmiştir (Tablo 9). Diğer karbon ve hidrojenlere ait ${ }^{13} \mathrm{C}$ ve ${ }^{1} \mathrm{H}$ NMR kimyasal kayna değerleri incelendiğinde literatür değerleri ile uyumlu olduğu gözlenmiştir [36-38].

Molekülün (3_8S5_m1_1_E) TD-SCF B3LYP metodu ve $6-311 \mathrm{G}++(\mathrm{d}, \mathrm{p})$ temel seti ile yaplan UV-Vis. hesaplaması sonucunda elde edilen verilerden tüm çözücülere ait spektrumların neredeyse bire bir örtüştüğü görülmektedir (Şekil 7). Tüm çözücülerde moleküle ait biri omuz olmak üzere iki pik gözlenmiştir. Vakum fazında ise çözücülerde omuz olarak gözlenen pikin ayrı olarak geldiği gözlenmiștir. Vakumdaki piklerin, çözücü fazı piklerinden farklı olması çözücü-çözünen etkileşiminden kaynaklanmaktadır. Farklı çözücü fazındaki spektrumların neredeyse örtüşmüş olmaları molekülün çözücü-çözünen etkileşiminden etkilenmediği anlaşılmaktadır. Tablo 10 'de verilen $\lambda_{2 \max }$ değerleri (361,3-345,9 nm) n- $\pi^{*}$ geçişlerine $\lambda_{1 \max }$ değerleri ise $(282,1-272,2 \mathrm{~nm}) \pi-\pi^{*}$ geçişlerine aittir. Vakum fazı ile çözücü fazları arasında dalga boylarında $\left(\lambda_{1 \max }\right.$ ve $\left.\lambda_{2 \max }\right)$ beklenilen kaymalar gözlenmiştir. $\pi-\pi^{*}$ geçişlerine $\left(\lambda_{1 \max }\right)$ ait kaymaların daha az $(3,3-9,9 \mathrm{~nm})$ olması, $\pi-\pi^{*}$ geçişlerinin çözücüden daha az etkilendiği anlamına gelmektedir. Aynı şekilde $n-\pi^{*}$ geçişlerine $\left(\lambda_{2 \max }\right)$ ait değerleri kaymalar ise daha fazla $(15,4-6,6 \mathrm{~nm})$ olduğu gözlenmiş ve bu durumun $n-\pi^{*}$ geçişlerinin çözücüden daha fazla etkilendiği anlamına gelmektedir. 
Vakumdaki B3LYP metodu ve 6-311G++(d,p) temel seti ile yapılan frekans hesaplamalarından elde edilen dipol moment değerlerinden 3_8S5_m1_1_E_freq formunda dipol moment değerlerinin yüksek olduğu (yaklaşık 5-6 Debye), 2_8S5_m1_1_K1_freq formunda yaklaşılk 3 Debye ve 1_8S5_m1_1_K2_freq ise en düşük olduğu (yaklaşık 1-2 Debye) gözlenmiştir. $\mathrm{Bu}$ sonuçlara göre 3_8S5_m1_1_E_freq formunda yük belli atom, grup ve bölgelerde yoğunlaşmış olduğu diğer iki formda ise moleküle yayıldığı anlaşılmaktadır. Hidrojen ve karbona kiyasla azot ve oksijenin elektronegatiflikleri daha yüksek olmasının molekül yapısındaki değișen fonksiyonel grupların (keto-enol formlarının) yük dağılımının da değişmesine neden olduğunu düşündürmektedir (Tablo 11).

Molekülün HOMO ve LUMO enerjileri sırası ile -8,813 $\mathrm{eV}(140,683 \mathrm{~nm})$ ve $-6,122 \mathrm{eV}(202,522 \mathrm{~nm})$ dir. $\Delta E_{\mathrm{GAP}}$ $=2,691$ ise olarak hesaplanmıştır. $\Delta E_{\mathrm{GAP}}$ enerji değerinin çok büyük olmaması bu molekülün yüksek reaktivite ve daha düşük kararlılık göstermesi, optik ve metalik iletkenlik gibi elektronik özelliklere sahip aday molekül olması anlamına gelmektedir. Ayrıca $\Delta E_{\mathrm{GAP}}=2,691(460,737 \mathrm{~nm})$ olması molekülün görünür bölgede ve mor renk aralığında bir renk göstermesi beklenmektedir. Görünür bölge, mor renk: $400 \mathrm{~nm}(3,10 \mathrm{eV})-435(2,85 \mathrm{eV})$ [39].

MEP hesaplama sonunda çizdirilen haritada molekülün elektronca zengin bölgeler kırmızl, elektronca yoksun bölgeler mavi ve aradaki sarı-yeşil renkler ise elektronca orta derecede olduğunu göstermektedir. Elektronca daha zengin halkanın sübstitüent içermeyen fenol halkasının ve elektronca daha az zengin halkanın ise nitro sübstitüe fenol halkasının olduğu görülmektedir. Oksijenlere bağlı hidrojenler ile imin grubun daki hidrojenlerin en fazla elekronca yoksun hidrojenler olduğu görülmektedir. Ayrıca imin grubu azotunun da elektronca yoksun olduğu görülmektedir. İmin azotu sübstitüe içermeyen fenole bağlı muhtemel molekül içi Hbağından dolayı elektronca yoksun olduğu söylenebilir. Ayrıca fenol hidrojeninin H-bağından dolayı fenol oksijenin de karbonile dönebileceği gösterdiği rezonanstan anlaşılmaktadır. Molekülün bir nükleofil veya elektronca zengin bir merkez varlığında ilk atağın fenol hidrojenlerinin olduğu görülmektedir. Elektrofilik bir atak veya elektronca yoksun bir merkez varlığında ise ilk etkilenecek atomların oksijen atomları ve sübstitüent içermeyen fenol halkası olduğu görülmektedir. Polar ve polar protik çözücü varlığında da bu merkezler etkin rol oynayacak merkezler olacağı söylenebilir. Ayrıca haritadan molekülün çok güçlü elektrofilik veya elektronca zengin ve yoksun merkezlerin olmadığı yük dağılımının molekülün geneline polarlaşma olmadan dağıldığı anlaşılmaktadır.

Şekil 5'te SASA şeklinden görüldüğü gibi, kırmızı bölgeler oksijen atomları üzerinde, mavi bölgeler ise İmin azotu, Nitro azotu ve nitroya bağlı karbon atomunda olduğu görülmektedir. $\mathrm{Bu}$ bölgeler, molekülün polar ve polar protik çözücülerle güçlü etkileşim merkezlerini gösterir. Ayrıca bu bölgeler biyolojik sistemler için de aktif merkezlerdir. $\mathrm{Bu}$ merkezler polar protik çözücüler ve protik merkezlere sahip biyolojik sistemler ile H-bağı yapacak merkezlerdir. $\mathrm{Bu}$ moleküllerin uygun merkezler ile etkileşimleri molekülün boyutuna ve geometrisine bağlı olarak değişik aktivite göstereceklerdir.

\section{Teşekkür}

Bu çalışmanın yazarları, 20ADP188 numaralı proje çalışmaları kapsamındaki desteklerinden dolayı Eskişehir Teknik Üniversitesi Bilimsel Araştırma Projeleri Komisyonu Başkanlığına teşekkür ederler. Yazarlar Anadolu Üniversitesi Bilimsel Araștırma Projesi (BAP No 1102F027) kapsamında alınan Gaussian 09 ve Gauss View 5.0 programını (Proje No: 1304F064) bu çalışmada kullandıklarından Anadolu Üniversitesi Bilimsel Araştırma Projeleri Komisyon Başkanlığına da teşekkür ederler.

\section{Etik Beyanı}

Bu çalışmada, "Yükseköğretim Kurumları Bilimsel Araştırma ve Yayın Etiği Yönergesi" kapsamında uyulması gerekli tüm kurallara uyulduğunu, bahsi geçen yönergenin "Bilimsel Araştırma ve Yayın Etiğine Aykırı Eylemler" başlığı altında belirtilen eylemlerden hiçbirinin gerçekleştirilmediğini taahhüt ederiz.

\section{Kaynakça}

[1] Kaltenbrunner, M., White, M.S., Głowacki, E.D., Sekitani, T., Someya, T., Sarıçiftçi, N.S., Bauer, S. 2012. Ultrathin And Lightweight Organic Solar Cells With High Flexibility. Nature Communications, 3(770), 1-7.

[2] Sidir, I., Gülseven Sidir, Y., Khan, N. Berber, H. 2021. Optoelectronic And Photonic Properties Of $\Pi$-Conjugated Benzonitrile Derivative Bis-Schiff Base By Solution Technique, Optik. International Journal for Light and Electron Optics, 241, 166825.

[3] Sidir, I., Sidir, Y. G., Berber, H., Demiray, F. 2019. Electronic Structure And Optical Properties of Schiff Base Hydrazone Derivatives By Solution Technique For Optoelectronic Devices: Synthesis, Experiment And Quantum Chemical Investigation. Journal of Molecular Structure, 1176, 31-46.

[4] Bin, H., Yao, J., Yang, Y., Angunawela, I., Sun, C., Gao, L. Ye, L., Qiu, B., Xue, L., Zhu, C., Yang, C., Zhang, Z. G,. Ade, H. 2018. High-Efficiency AllSmall-Molecule Organic Solar Cells Based On An Organic Molecule Donor With Alkylsilyl-Thienyl Conjugated Side Chains. Advanced Materials, 30(27) 1706361 . 
[5] Berhanu, A. L., Mohiuddin, G. I., Malik, A. K., Aulakh, J. S., Kumar, V., Kim, K. H. 2019. A review of the applications of Schiff bases as optical chemical sensors. Trac-Trends in Analytical Chemistry, 116, 74-91.

[6] Kajal, A., Bala, S., Kamboj, S., Sharma, N., Saini, V. 2013. Review Article: Schiff bases: A versatile pharmacophore. Journal of Catalysis, 893512, 114.

[7] Sidir, Y. G., Pirbudak, G., Berber, H., Sidir, I. 2017. Study on Electronic and Photophysical Properties of Substitute-( (2Phenoxybenzylidene)Amino)Phenol Derivatives: Synthesis, Solvatochromism, Electric Dipole Moments And DFT Calculations. Journal of Molecular Liquids, 242, 1096-1110.

[8] Liua, Y., Maoa, L., Yang, S., Liu, M., Huang, H., Wen, Y., Deng, F., Li, Y., Zhang, X., Wei, Y. 2018. Synthesis and Biological Imaging of Fluorescent Polymeric Nanoparticles with AIE Feature via The Combination of RAFT Polymerization and Post-Polymerization Modification, Dyes and Pigments, 158, 79-87.

[9] Gowda, A., Roy, A., Kumar, S. 2017. Synthesis and Mesomorphic Properties of Novel Schiff Base Liquid Crystalline EDOT Derivatives. Journal of Molecular Liquids, 225, 840-847.

[10] Liu, X., Hamon, J. R. 2019. Recent Developments In Penta-, Hexa- And Heptadentate Schiff Base ligands and Their Metal Complexes. Coordination Chemistry Reviews, 389, 94-118.

[11] Abdel-Rahman, L. H., Abu-Dief, A. M., Aboelez, M. O., Hassan Abdel-Mawgoud, A. A. 2017. DNA Interaction, Antimicrobial, Anticancer Activities and Molecular Docking Study of Some New VO(II), Cr(III), Mn(II) And Ni(II) Mononuclear Chelates Encompassing Quaridentate Imine Ligand. Journal of Photochemistry and Photobiology B-Biolog, 170, 271-285.

[12] Utreja, D., Singh, S., Kaur, M., 2015. Schiff Bases and their Metal Complexes as Anti-Cancer Agents: A Review. Current Bioactive Compounds, 11(4), 215-230.

[13] Aydoğdu, A., Uysal, U. D., Berber, H. 2017. Newly Synthesized Schiff Bases: Structure Analysis, Theoretical IR, UV, 1H, 13C-NMR Spectra and Structure-Activity Relationship. Chemical Sciences Journal Open Access, 8(2), 98.

[14] Ercengiz, D., Berber, H., Uysal U. D. 2017. Theoretical IR, UV, 1H And 13C-NMR Spectra Of Certain Schiff Bases Derived Substituted-2Aminophenol and Hydroxyl Benzaldehyde. Chemical Sciences Journal Open Access, 8(2), 102.

[15] Uysal, U. D., Berber, H., Ercengiz, D. 2018. Theoretical Investigation on Solvent Dependent
Shift and Electronic Transition Properties of Certain Schiff Bases. Journal of the Turkish Chemical Society, Section A, 4(1), 111-130.

[16] Berber, H., Aydoğdu Erdönmez, A., Uysal, U. D. 2020. 2-Etoksi-6-[(E)-[(2Hidroksifenil)imino]metil]fenol Türevi Schiff Bazlarının Sentezi ve Teorik Çalıșmalar (Synthesis and Theoretical Studies of 2-Ethoxy-6[(E)-[(2-Hydroxyphenyl)imino]methyl]phenol Derivative Schiff Bases). Süleyman Demirel Üniversitesi Fen Bilimleri Enstitüsü Dergisi, 24(2), 419-431.

[17] Uysal, U. D., Ercengiz, D., Karaosmanoğlu, O., Berber, B., Sivas, H., Berber, H. 2021. Theoretical And Experimental Electronic Transition Behaviour Study of 2-((4(Dimethylamino)Benzylidene)Amino)-4Methylphenol and Its Cytotoxicity. Journal of Molecular Structure, 1227.

[18] Argauer, R. J., White, C. E. 1964. Effect of Substituent Groups on Fluorescence of Metal Chelates. Analytıcal Chemistry, 36(11), 21412144.

[19] Kianfar, A. H., Paliz, M., Roushani, M., Shamsipur, M. 2011. Synthesis, Spectroscopy, Electrochemistry and Thermal Study of Vanadyl Tridentate Schiff Base Complexes. Spectrochimica Acta, Part A: Molecular and Biomolecular Spectroscopy, 82(1), 44-48.

[20] Mandhare, D. B., Barhate, V. D. 2016. Development of Extractive Spectrophotometric Method For The Determination Of İron (III) With Schiff Base 2-[(2-Hydroxyphenylimino) Methyl]4-Nitrophenol. International Journal of Current Pharmaceutical Research, 8(4), 89-91.

[21] Mandhare, D. B., Barhate, V. D. 2016. Development of Extractive Spectrophotometric Method for The Determination of Manganese (II) with Schiff Base 2-[(2Hydroxyphenylimino)Methyl]-4-Nitrophenol. European Journal of Biomedical and Pharmaceutical Sciences, 3(3), 421-423.

[22] Mandhare, D. B., Barhate, V. D. 2015. Development of Extractive Spectrophotometric Method for The Determination of Ruthenium (III) with Schiff Base 2-[(2-Hydroxyphenylimino) Methyl]-4-Nitrophenol. Journal of Applicable Chemistry, 4 (4), 1243-1247.

[23] Fasina, T. M., Ejiah, F. N., Dueke-Eze, C. U., Idika, N. 2013. Substituent Effect on The Antimicrobial Activity of Schiff Bases Derived drom 2Aminophenol and 2-Aminothiophenol. International Journal of Biological Chemistry, 7 (2), 79-85.

[24] Ercengiz, D. 2019. Alüminyumun orto hidroksi schıff bazları kullanılarak spektrofotometrik tayinleri, Eskişehir Teknik Üniversitesi, 
Lisansüstü Eğitim Enstitüsü, Yüksek Lisans Tezi, 84s, Eskișehir.

[25] Aydoğdu Erdönmez, A. 2019. Sübstitüe 2aminofenol ve hidroksi benzaldehitten türetilen Schiff bazı ile alüminyumun spektrofotometrik tayini, Anadolu Üniversitesi, Lisansüstü Eğitim Enstitüsü, Yüksek Lisans Tezi, 83s, Eskişehir.

[26] Sübstitüe 2-aminofenol ile sübstitüe hidroksi benzaldehit türevi bileșiklerinden olușan bazı Schiff bazlarının sentezi, spektroskopik çalıșması ve çeşitli numunelerde metal tayininde kullanımının araştırılması. 1509F633 Proje Yürütücülüğü (genel amaçlı proje), 25.12.201501.12.2017.

[27] Berber, H., Uysal, U. D., Aydoğdu, A. 2017. Theoretical Study on The Stability, Acidity Constants and Molecular Electronic Properties of Certain 0-Hydroxy Schiff Bases and Their Tautomers. Journal of the Turkish Chemical Society, Section A', 4 (1), 77-92.

[28] CS ChemBioDraw Ultra 16,0,1,4 for Microsoft Windows.

[29] Frisch, M. J., Trucks, G. W., Schlegel, H. B., Scuseria, G. E., Robb, M. A., Cheeseman, J. R., Scalmani, G., Barone, V, Mennucci B, Petersson GA, Nakatsuji $H$, Caricato, M., Li X., Hratchian, H. P., Izmaylov, A. F., Bloino, J., Zheng, G., Sonnenberg, J. L., Hada, M., Ehara, M., Toyota, K., Fukuda, R., Hasegawa, J., Ishida, M., Nakajima, T., Honda, Y., Kitao, O., Nakai, H., Vreven, T., Montgomery, Jr J. A,, Peralta, J. E., Ogliaro, F., Bearpark, M., Heyd, J. J., Brothers, E., Kudin, K. N., Staroverov, V. N., Kobayashi, R., Normand, J., Raghavachari, K., Rendell, A., Burant, J. C., Iyengar, S. S., Tomasi, J., Cossi, M., Rega, N., Millam, J. M., Klene, M., Knox, J. E., Cross, J. B., Bakken, V., Adamo, C., Jaramillo, J., Gomperts, R., Stratmann, R. E., Yazyev, O., Austin, A. J., Cammi, R., Pomelli, C., Ochterski, J. W., Martin, R. L., Morokuma, K., Zakrzewski, V. G., Voth, G. A., Salvador, P., Dannenberg, J. J., Dapprich, S., Daniels, A. D., Farkas, O., Foresman, J. B., Ortiz, J. V., Cioslowski, J., Fox, D. J., 2009. Gaussian, Inc., Wallingford CT 06492 USA.
[30] Dennington, R., Keith, T. A., Millam, J. M. 2009. GaussView, Version 5, Semichem Inc., Shawnee Mission, KS.

[31] MarvinSketch 19.27.0, https://chemaxon.com/ (Erişim Tarihi: 02.07.2021).

[32] MOPAC2016, James J. P. Stewart, Stewart Computational Chemistry, Colorado Springs, CO, USA, HTTP://OpenMOPAC.net (2016) (Erişim Tarihi: 02.07.2021)

[33] Erdik, E. 2015. Organik Kimyada Spektroskopik Yöntemler. 5. Baskı, Gazi Kitabevi Ankara.

[34] Infrared Spectroscopy Absorption Table, https://chem.libretexts.org/Ancillary_Materials /Reference/Reference_Tables/Spectroscopic_Pa rameters/Infrared_Spectroscopy_Absorption_Ta ble (Erişim Tarihi: 02.07.2021).

[35] IR Spectrum Table \& Chart, https://www.sigmaaldrich.com/TR/en/technic al-documents/technical-article/analyticalchemistry/photometry-and-reflectometry/irspectrum-table (Erişim Tarihi: 02.07.2021).

[36] Balcı, M. 2015. Nükleer Manyetik Rezonans Spektroskopisi. ODTÜ Geliștirme Vakfı Yayıncılık-Akademik Kitaplar, ISBN: 97897570642372007, Ankara, Ender Erdik, Organik Kimyada Spektroskopik Yöntemler, 5. Baskı, Gazi Kitabevi, Ankara.

[37] https://www2.chemistry.msu.edu/courses/ cem251/SS13_HOVIG/Spectroscopy\%20tables.p df (Erişim Tarihi: 02.07.2021).

[38] https://www2.chemistry.msu.edu/faculty/ reusch/orgpage/nmr.htm (Erişim Tarihi: 02.07.2021).

[39] Christie, R. M. 2001. Colour Chemistry. 2nd editiom. Heriot-Watt University, Scottish Borders Campus, Galashiels, UK, The Royal Society of Chemistry, Thomas Graham House, Science Park, Milton Road, Cambridge, CB40WF, UK, 333s. 